\title{
Effect of inbreeding depression on bull sperm quality and field fertility
}

\author{
Jesús Dorado ${ }^{\mathrm{A}}$, Rosa Morales Cid ${ }^{\mathrm{B}}$, Antonio Molina ${ }^{\mathrm{B}}$, Manuel Hidalgo $^{\mathrm{A}}$, \\ Julia Ariza ${ }^{\mathrm{C}}$, Miguel Moreno-Millán ${ }^{\mathrm{B}}$ and Sebastián Demyda-Peyrás ${ }^{\mathrm{D}, \mathrm{E}^{\prime}}$ \\ A Department of Animal Medicine and Surgery, University of Cordoba, CN IV KM 396 - Campus \\ Rabanales, Fco. Santisteban building, CP 14071, Cordoba, Spain. \\ ${ }^{B}$ Department of Genetics, University of Cordoba, CN IV KM 396 - Campus Rabanales, \\ Gregor Mendel Building, CP 14071, Cordoba, Spain. \\ ${ }^{C}$ Department of Cell Biology, Physiology and Immunology, University of Cordoba, CN IV KM \\ 396 - Campus Rabanales. Gregor Mendel Building. CP 14071. Cordoba, Spain. \\ D Instituto de Genetica Veterinaria (IGEVET), CCT La Plata, CONICET - Facultad de Ciencias \\ Veterinarias - Universidad de La Plata, Buenos Aires, Argentina. \\ ${ }^{\mathrm{E}}$ Corresponding author. Email: sebass@uco.es
}

\begin{abstract}
The present study investigated the effect of inbreeding depression on sperm quality using automated and objective methods and subsequent effects on beef bull field fertility. Individual inbreeding coefficient (F) values and field fertility data were determined using a dataset of AI bulls belonging to the Spanish Retinta Breeders Association (Asociación Nacional de Criadores de Ganado Vacuno Selecto de Raza Retinta (ANCRE)). Animals were clustered in two groups according to the $\mathrm{F}$ values as follows: (1) a high inbreeding group (HI; F $\geq 13.5 \%$, mean 16.3); and (2) a noninbreeding group ( $\mathrm{NI} ; \mathrm{F}=0 \%$ ). In total, 17 different assessments were performed in both experimental groups, including evaluation of sperm morphology, acrosomal and DNA status, sperm plasma membrane integrity and function (hypoosmotic swelling test), 10 kinetic parameters and the structure of sperm subpopulations. Sperm morphology, acrosomal and DNA status and osmotic tolerance were similar in both groups. Three velocity parameters (curvilinear velocity, straight line velocity and average path velocity) and the amplitude of lateral head displacement were higher in $\mathrm{HI}$ $(P<0.05)$. Cluster analysis of kinematic parameters revealed three different sperm subpopulations (sP1, sP2 and sP3), with the proportion of the sP1 population (highly active but non-progressive spermatozoa) being significantly $(P<0.05)$ higher in the HI group. Field fertility was assessed using two calving record datasets. In a smaller database including only bulls evaluated in the present study, there was a significant increase in the calving interval of cows sired with HI bulls. Conversely, in an extended genetic analysis of the ANCRE database, inbreeding only explained a small part of the variation in calving interval, and the results of regression analysis were not significant among bulls. The findings of the present study suggest that high inbreeding levels have a moderate effect on bull semen quality, with an increased percentage of highly active but non-progressive spermatozoa, but only when $\mathrm{F}$ values reached a certain threshold. This motility pattern could explain, in part, the higher calving interval produced by inbred bulls under field conditions.
\end{abstract}

Additional keywords: calving interval, cattle, computer-aided sperm analysis (CASA), DNA fragmentation, genetic trait, sperm function, sperm morphology, sperm subpopulations.

Received 7 August 2015, accepted 9 November 2015, published online 18 December 2015

\section{Introduction}

Sperm quality is one of the most important traits defining the reproductive potential of bulls. It is normally determined by a group of characteristics including morphology, motility, viability and DNA function (Söderquist et al. 1996; Gil et al. 2000). It is well known that sperm quality is affected by environmental factors, such as the age of the animal, fitness and absence of diseases (Brito et al. 2002). However, sperm quality is also affected by the genetic pool of the individual, but shows only low to moderate heritability (Mathevon et al. 1998), which is why it is rarely included in cattle selection schemes (Karoui et al. 2011). In practice, candidate sires are evaluated before they are included in AI programs, discarding those that do not meet certain minimum sperm quality standards because of genetic causes (Rodriguez-Martinez and Larsson 1998).

Inbreeding depression, a consequence of breeding related individuals, results in reduced viability and adaptability in a given population (Kristensen et al. 2010). According to 
Charlesworth and Willis (2009), the genetic causes of inbreeding depression may be due to three different possibilities: (1) increased expression of deleterious recessive alleles (partial dominance); (2) fitness superiority of heterozygotes over homozygotes (overdominance); or (3) increased possibility of favourable gene combinations in heterozygotes (epistasis). Although the relative contribution of each cause to inbreeding depression remains unclear, it is well known that inbred animals show reduced flexibility in coping with environmental challenges (Lacy 1997; Leberg and Firmin 2008), decreased fitness and mean phenotypic traits and impaired reproductive success across wild, captive, domestic and experimental populations (O'Grady et al. 2006; Leroy 2014). This phenomenon is particularly important in cattle, where the high intensity of current selection programs and the use of autochthonous populations with reduced census have brought about a rapid increase in genetic relationships among individuals (Hansen 2000; RoderoSerrano et al. 2013). In these animals, inbreeding depression is expressed in different ways, such as reduced viability and lifetime performance in beef cattle (Smith et al. 1998) and decreased lifetime milk production in dairy cattle (Thompson et al. 2000). Nevertheless, this genetic trait has not been considered to any great extent in selection schemes, which primarily focus on improving production traits (Gandini et al. 2014), leading to a slow but steady increase in inbreeding depression over time (Sørensen et al. 2005; Stachowicz et al. 2011).

There is general agreement that fertility is negatively affected by inbreeding (Keller and Waller 2002). This impairment is particularly important in endangered wild animals, for which inbreeding levels are very high (Cassinello et al. 1998; RuizLopez et al. 2010). However, only a few studies have analysed the effect of inbreeding on bull sperm quality and contradictory results have been reported (Losdat et al. 2014). For example, Flade and Zeller (1992) demonstrated that sperm quality was not affected in high inbreeding bulls (inbreeding coefficient $(\mathrm{F})=25 \%$, produced experimentally) compared with their noninbred half-brothers $(\mathrm{F}=0 \%)$. In contrast, Maximini et al. (2011) more recently described a low negative correlation between inbreeding and sperm quality in Simmental bulls.

On the basis of this background information, the aim of the present study was to perform a comprehensive evaluation of the effects of inbreeding on bull sperm motility (using computeraided sperm analysis (CASA)) and DNA integrity (using flow cytometry). Concurrently, we assessed sperm viability and the status of both acrosomal and plasma membranes. Finally, we determined the effects of inbreeding on in vivo fertility in our experimental animals as well as in a reproductive dataset of AI commercial beef bulls with broad genealogy and reproductive records over several seasons.

\section{Materials and methods}

Animals

Genealogical data from 159 sperm donor bulls belonging to the Spanish Retinta Breeders Association (Asociación Nacional de Criadores de Ganado Vacuno Selecto de Raza Retinta (ANCRE)) AI program were analysed. Individual $\mathrm{F}$ values
(Wright 1931) and the number of fully traced, maximum number of generations traced and the equivalent complete generations (ECG) for each animal were estimated by ENDOG (v4.8; Gutierrez and Goyache 2005) using all known generations. Thereafter, 11 bulls with at least two complete generations and 2.5 ECG and available frozen semen doses were selected and classified into two groups based on $\mathrm{F}$ values as follows: (1) animals with at least $13.5 \%$ consanguinity $(\mathrm{F}=16.3 \pm 0.9 \%$ (mean \pm s.e.m.); minimum $13.5 \%$, maximum $18.7 \%$ ), which were classified as the high inbreeding (HI) group $(n=6)$; and (2) animals without consanguinity $(\mathrm{F}=0 \%)$, which were classified as the non-inbreeding (NI) group $(n=5)$. The mean ( \pm s.e.m.) ECG for the HI and LE groups were $5.2 \pm 0.6$ and $4.1 \pm 0.6$, respectively. Minimum consanguinity in the HI group $(\mathrm{F}=13.5 \%)$ was higher than the equivalent to a half-sibling cross $(12.5 \%)$, which is considered the threshold value from which serious fitness problems derived from inbreeding depression appear (Sewalem et al. 2006).

\section{Semen samples}

In all, 55 frozen semen samples (five per bull) were analysed. Semen was collected from individuals between 20 and 30 months of age with a positive breeding soundness examination score and was frozen at the Centro de Selección y Reproducción Animal (CENSYRA; Badajoz, Spain) following the procedures of ANCRE's AI program. Frozen semen was thawed at $37^{\circ} \mathrm{C}$ in a water bath for $1 \mathrm{~min}$ and diluted in Biladyl A (Minitüb, Tiefenbach, Germany) to reach a working concentration of $25 \times 10^{6}$ spermatozoa $\mathrm{mL}^{-1}$. Only samples with acceptable post-thawing sperm membrane integrity and motility $(>40 \%$ sperm membrane integrity and $>50 \%$ total motility) were used.

\section{Semen evaluation \\ Sperm morphology}

The percentage of spermatozoa with abnormal morphology was estimated on Diff-Quik-stained smears (Baxter DADE Diagnostics, Düdingen, Switzerland), as described previously (Hidalgo and Dorado 2009). The proportion of spermatozoa with normal morphology (NSM) and abnormal morphology (ASM) was recorded. Two independent replicates of at least 200 spermatozoa were assessed for each sample.

\section{Plasma membrane integrity}

Sperm plasma membrane integrity was assessed using a Vital-Test kit (Halotech, Madrid, Spain) according to the manufacturer's instructions under a fluorescence microscope (BX40; Olympus, Tokyo, Japan) using a 460-490-nm excitation filter. Two staining patterns were discerned: (1) spermatozoa with a green-stained head were determined to be viable spermatozoa (VS); and (2) spermatozoa with red-stained heads were recorded as dead spermatozoa (DS). Two independent replicates of at least 200 spermatozoa were assessed for each sample.

\section{Plasma membrane function}

The function of the sperm plasma membrane was assessed using the hypo-osmotic swelling (HOS) test (Revell and Mrode 1994). Samples were incubated for $1 \mathrm{~h}$ at $38.5^{\circ} \mathrm{C}$ in 
hypo-osmotic solution (100 mOsmol $\left.\mathrm{mL}^{-1}\right)$ containing $1: 1$ (v/v) fructose : sodium citrate. Thereafter, $20 \mu \mathrm{L}$ solution was smeared on a clean slide, dried and evaluated at a magnification of $\times 400$. Spermatozoa with unaltered tail morphology were classified as negative (HOS-), whereas those showing a coiled tail were classified as positive (HOS +$)$. Two independent replicates of at least 200 spermatozoa were assessed for each sample.

\section{Acrosome membrane integrity}

Acrosome integrity was assessed using a standard protocol (Demyda-Peyras et al. 2012). A droplet of diluted sample was smeared onto a microscopic slide, air dried, fixed and permeabilised with $70 \%(\mathrm{v} / \mathrm{v})$ ethanol for $30 \mathrm{~s}$. Thereafter, $30 \mu \mathrm{L}$ of a staining mixture (1 part propidium iodide (PI; $0.1 \mathrm{mg} \mathrm{mL}^{-1}$ ) and 2 parts isothiocyanate-labelled peanut (Arachis hypogaea) agglutinin $\left.\left(0.1 \mathrm{mg} \mathrm{mL}^{-1}\right)\right)$ was spread over each smear and samples were incubated in a dark and humid chamber at $4^{\circ} \mathrm{C}$ for $30 \mathrm{~min}$. Preparations were subsequently washed, mounted with Vectashield (Vector Laboratories, Peterborough, UK) and scored under an epifluorescence microscope (BX40; Olympus) at $\times 400$ magnification. Two sperm subpopulations were identified: (1) spermatozoa with a uniform green fluorescence of the acrosomal cap (acrosome-intact spermatozoa (AIS)); and (2) spermatozoa with a disrupted, patch-like, green fluorescence staining in the acrosomal cap, a fluorescent band at the equatorial segment or no fluorescence (acrosome-reacted spermatozoa (ARS)). All spermatozoa showed red fluorescence because of counterstaining with PI. Two independent replicates of at least 200 spermatozoa were assessed for each sample.

\section{Chromatin integrity}

The percentage of altered DNA (strand breaks) was assessed using the acridine orange (AO) sperm chromosome structure assay (SCSA; Evenson and Jost 2000). Immediately after thawing, samples were placed on ice and diluted separately in TNE buffer $(0.015 \mathrm{M} \mathrm{NaCl}, 0.01 \mathrm{M}$ Tris and $0.001 \mathrm{M}$ EDTA, pH 6.8) to a final concentration of $1 \times 10^{6}$ spermatozoa $\mathrm{mL}^{-1}$. A $200-\mu \mathrm{L}$ aliquot of sperm solution was treated with $400 \mu \mathrm{L}$ acid detergent solution $(0.08 \mathrm{M} \mathrm{HCl}, 0.15 \mathrm{M} \mathrm{NaCl}$ and $0.1 \%(w / v)$ Triton $\mathrm{X}-100, \mathrm{pH} 1.2)$ and then after exactly $30 \mathrm{~s} 1.2 \mathrm{~mL}$ AO staining solution was added $(6 \mathrm{mg}$ AO per $\mathrm{mL}$ buffer $(0.037 \mathrm{M}$ citric acid, $0.12 \mathrm{M} \mathrm{Na}_{2} \mathrm{PO}_{4}, 1.1 \mathrm{mM}$ disodium EDTA and $0.15 \mathrm{M} \mathrm{NaCl}$ ), $\mathrm{pH}$ 6.0). Samples were analysed in an EPICS XL cytometer (Beckmann Coulter, Miami, FL, USA) containing a 488-nm dichroic long-pass filter, a 488-nm blocking filter, a 550-nm dichroic long-pass filter and a 525-nm band pass filter for the first fluorescent channel (FL1), a 600-nm dichroic long-pass filter and a $575-\mathrm{nm}$ band pass filter for the second fluorescent channel (FL2), a 645-nm long-pass filter and a 620-nm band pass filter for the third fluorescent (FL3) channel and a 675-nm longpass filter for the fourth fluorescent channel (FL4). Fluorescence was recorded at FL1 and FL4. Two independent replicates per bull of at least 20000 spermatozoa were assessed for each sample at an average flow rate of 200 spermatozoa per second. Data were collected individually in list mode and transformed to plain text using MFI software (Martz 1992-2001). The chromatin damage (DNA fragmentation index; DFI)) and high DNA stainability (HDS), associated to the percentage of immature sperm were determined by analysing the ratio of red:green fluorescence, as described by Rybar et al. (2010).

\section{CASA}

Sperm motility was assessed using a CASA system (Sperm Class Analyzer; Microptic, Barcelona, Spain). Three consecutive 5 - $\mu \mathrm{L}$ drops of each semen working sample were evaluated using a phase contrast microscope (Eclipse 50i; Nikon, Tokyo, Japan) with a prewarmed stage at $37^{\circ} \mathrm{C}(\times 100$ magnification $)$. Three drops and two microscopic fields per drop were randomly analysed, including a minimum number of 200 spermatozoa. The analysis was performed on 25 consecutive digital images captured in $1 \mathrm{~s}$ from a single microscope field.

Parameters of the analysis software were set according to Kathiravan et al. (2011). Briefly, spermatozoa with mean average path velocity (VAP) $<10 \mu \mathrm{m} \mathrm{s}^{-1}$ were considered immotile. Spermatozoa with a VAP $>90 \mu \mathrm{m} \mathrm{s}^{-1}$ were considered rapid, and spermatozoa deviating $<25 \%$ from a straight line were designated as linear motile. The following kinetic traits were assessed: curvilinear velocity (VCL), the total distance travelled by the sperm head per unit time; straight line velocity (VSL), the net distance gain of the sperm head per unit time; VAP, the length of a derived 'average' path of sperm head movement per unit time; wobble (WOB), calculated as (VAP/ $\mathrm{VCL}) \times 100$; linearity $(\mathrm{LIN})$, calculated as $(\mathrm{VSL} / \mathrm{VCL}) \times 100$; straightness $(\mathrm{STR})$, calculated as $(\mathrm{VSL} / \mathrm{VAP}) \times 100$; beat cross frequency $(\mathrm{BCF})$, the number of times the curvilinear path crosses the average path per unit time; approximation of the flagellar beat frequency for seminal sperm (in $\mathrm{Hz}$ ); and amplitude of lateral head displacement (ALH), the width of the head movement envelope.

\section{Classification, ordination and identification of sperm subpopulations}

Motility data from all individual spermatozoa assessed were included in this analysis and initially grouped in two categories based on F values (22 190 spermatozoa from HI bulls and 23097 spermatozoa from NI bulls). A four-step clustering procedure was used to classify the spermatozoa in the dataset (45287 in total) into a reduced number of subpopulations according to their motility patterns as described previously by MartinezPastor et al. (2005). All determinations were performed using SAS/STAT software package release 9.0 (SAS Institute, Cary, NC, USA). First, the PRINCOMP procedure was used for principal component analysis (PCA). Thereafter, a nonhierarchical cluster analysis (FASTCLUS procedure) was performed using the selected principal components as variables. Then, the processed data were reclustered by hierarchical methods (CLUSTER procedure) using the average linkage method (AVERAGE) for joining clusters. To determine the final number of subpopulations (sP; Step 4), we studied the evolution along the clustering process of three statistics provided by CLUSTER (pseudo-t2, pseudo-F and cubic clustering criterion) looking for certain types of consensus among them, specifically local peaks of the cubic clustering criterion 
and pseudo-F statistics combined with a small pseudo- $\mathrm{t} 2$ value and a larger pseudo-t 2 for the next cluster fusion.

\section{Statistical analysis}

All statistical analyses were performed using SAS/STAT (SAS Institute). Results are expressed as the mean \pm s.e.m. Sperm parameters were compared between groups (HI vs NI) using a nested general linear model (GLM) with group (fixed factor) and bull (nested in group) as the random factor. The parameter SGoF+ (Carvajal-Rodriguez and de Uña-Alvarez 2011) was used to control the false discovery rate (FDR) of the $P$-values at a significance level of 5\% and an FDR of 5\%. The percentage of sperm subpopulations in the HI and LE groups was compared by Fisher's exact test (FREQ procedure).

\section{Assessment of bull fertility under field conditions}

Calving intervals $(\mathrm{CI})$ were estimated based on mating records of the ANCRE. Records from 824 cows inseminated or mated by HI $(n=490)$ and NI $(n=334)$ bulls were compared using GLM. Group (HI or NI) and bull (nested in group) were included as fixed and random factors, respectively. Age of the cow at delivery was included as a covariate.

\section{Genetic analysis}

A subsequent broader genetic analysis included the CI of 5230 cows inseminated or mated by 743 bulls (159 semen donors) belonging to the ANCRE dataset. The effects of several factors and the genetic component of CI were analysed with an animal model using Bayesian methodology as follows:

$$
y=X b+Z_{1} a_{1}+Z_{2} a_{2}+W p+e
$$

where $y$ is observed CI, $b$ is systematic fixed effects, $a_{1}$ and $a_{2}$ are cow and bull additive genetic effects, respectively (11 445 levels), $p$ is bull permanent environmental effects (743 levels), $e$ is residual effects and $X, Z$ and $W$ are incidence matrices.

The systematic fixed effects $(b)$ included a random contemporary group effect (herd $\times$ year $\times$ breeding season; 1323 levels) with four different seasons (December-March, AprilJune, July + August and September-November) defined according to the weather characteristics of the region, and the fixed age effect of the cow. Inbreeding coefficients for both cow and bull were obtained by the tabular method (Tier 1990) and included as covariates.

The prior distributions of $a=\left(a_{1}\right.$ and $\left.a_{2}\right), p$ and $e$ were $N(0$, $\left.A \otimes G_{\mathrm{o}}\right), N\left(0, I \sigma_{\mathrm{p}}^{2}\right)$ and $N\left(0, I \sigma_{\mathrm{e}}^{2}\right)$, respectively, where $G_{\mathrm{o}}$ is a (co)variance matrix for the additive genetic components on $\mathrm{CI}_{12}$ of cow and bull. Gibbs sampling algorithm was used to make Bayesian inferences for the parameters of interest. Data analysis consisted of a long chain of $10^{6}$ iterations, a burn-in of 500000 rounds and a thin of 10 iterations using TM software (Legarra et al. 2008).

\section{Results}

\section{Sperm morphology and function}

Inbreeding did not induce differences $(P>0.05)$ in sperm morphology, acrosomal and plasma membrane integrity or
Table 1. Morphological and functional assessment of sperm samples from inbred (HI; $n=30$ ) and non-inbred (NI; $\boldsymbol{n}=25$ ) bulls Results are expressed as the mean \pm s.e.m. $* P<0.05$ compared with HI bulls. ASM, abnormal sperm morphology; VS, viable spermatozoa; AIS, acrosome-intact spermatozoa; HOS + , hypo-osmotic swelling test positive

\begin{tabular}{lcc}
\hline Sperm parameters & HI & NI \\
\hline$\%$ ASM & $33.15 \pm 2.68$ & $36.07 \pm 2.23$ \\
$\%$ VS & $47.70 \pm 1.70$ & $50.85 \pm 1.94$ \\
$\%$ AIS & $82.97 \pm 1.68$ & $80.15 \pm 2.09$ \\
$\%$ HOS + spermatozoa & $42.20 \pm 2.07$ & $47.23 \pm 3.07 *$ \\
\hline
\end{tabular}

Table 2. Sperm chromatin structure assay results from inbred (HI; $n=30)$ and non-inbred (NI; $n=25$ ) bulls

\begin{tabular}{ccccccc}
\hline & \multicolumn{3}{c}{ DNA fragmentation index (\%) } & \multicolumn{3}{c}{ High DNA stainability (\%) } \\
& Mean & s.e.m. & Range & Mean & s.e.m. & Range \\
\hline HI bulls & 2.99 & $1.48 \times 10^{-6}$ & $2.01-5.36$ & 2.09 & $2.26 \times 10^{-6}$ & $0.17-4.95$ \\
NI bulls & 3.01 & $2.43 \times 10^{-6}$ & $0.98-6.02$ & 1.82 & $2.48 \times 10^{-6}$ & $0.28-3.47$ \\
\hline
\end{tabular}

Table 3. Motility analysis of sperm samples from inbred (HI; $\boldsymbol{n}=\mathbf{3 0}$ ) and non-inbred (NI; $n=25)$ bulls

Results are expressed as the mean \pm s.e.m. Within rows, values with different superscript letters differ significantly at $P<0.05$ after control of the false discovery rate at $5 \%$. VCL, curvilinear velocity; VSL, straight line velocity; VAP, average path velocity; ALH, amplitude of lateral head displacement; $\mathrm{BCF}$, beat cross frequency

\begin{tabular}{lcc}
\hline Sperm parameters & HI bulls & NI bulls \\
\hline MOT $^{\mathrm{A}}(\%)$ & $76.68 \pm 1.97$ & $79.77 \pm 2.10$ \\
PMOT $^{\mathrm{B}}(\%)$ & $53.43 \pm 1.93$ & $50.86 \pm 2.58$ \\
\left.${\text { VCL }\left(\mu \mathrm{m} \mathrm{s}^{-1}\right)}^{-1}\right)$ & $77.73 \pm 1.69^{\mathrm{a}}$ & $69.64 \pm 2.74^{\mathrm{b}}$ \\
VSL $\left(\mu \mathrm{m} \mathrm{s}^{-1}\right.$ & $40.60 \pm 0.99^{\mathrm{a}}$ & $37.34 \pm 2.11^{\mathrm{b}}$ \\
VAP $\left(\mu \mathrm{m} \mathrm{s}^{-1}\right)$ & $55.93 \pm 1.41^{\mathrm{a}}$ & $50.46 \pm 2.29^{\mathrm{b}}$ \\
Linearity $(\%)$ & $45.04 \pm 0.89$ & $44.48 \pm 1.06$ \\
Straightness $(\%)$ & $62.73 \pm 0.81$ & $62.34 \pm 0.84$ \\
Wobble $(\%)$ & $67.60 \pm 1.10$ & $66.64 \pm 0.80$ \\
ALH $(\mu \mathrm{m})$ & $2.81 \pm 0.08^{\mathrm{a}}$ & $2.61 \pm 0.07^{\mathrm{b}}$ \\
BCF $(\mathrm{Hz})$ & $6.81 \pm 0.14$ & $6.46 \pm 0.16$ \\
\hline
\end{tabular}

${ }^{\mathrm{A}}$ Total motility (MOT) was defined as spermatozoa with a mean VAP $>15 \mathrm{~mm} \mathrm{~s}^{-1}$.

${ }^{\mathrm{B}}$ Progressive motility (PMOT) was defined as spermatozoa with a VAP $>50 \mathrm{~mm} \mathrm{~s}^{-1}$ and straightness $>75 \%$.

results of the HOS test between the HI and NI groups (Table 1). In addition, inbreeding had no significant effect on DNA structure (DFI), despite the large number of spermatozoa analysed $(P>0.05$; Table 2$)$, or on the percentage of immature spermatozoa (HDS). The variability in both these parameters was similar between the HI and LE groups.

Motility analysis

Only four CASA-derived parameters were affected by inbreeding (Table 3). VCL, VAP, VSL and ALH were higher $(P<0.05)$ in $\mathrm{HI}$ compared with NI bulls. Two principal 
Table 4. Motility parameters for the three sperm subpopulations (sP1, sP2 and sP3) defined after pattern analysis in semen samples from inbred (HI; $n=30)$ and non-inbred (NI; $n=25)$ bulls

Results are expressed as the mean \pm s.e.m. Within rows, values with different superscript letters differ significantly $(P<0.05)$. The total number of spermatozoa analysed was 45287 . VCL, curvilinear velocity; VSL, straight line velocity; VAP, average path velocity; ALH, amplitude of lateral head displacement; BCF, beat cross frequency

\begin{tabular}{lccc}
\hline Sperm parameter & $\mathrm{sP1}$ & $\mathrm{sP} 2$ & $\mathrm{sP3}$ \\
\hline No. spermatozoa & 19942 & 7720 & 17625 \\
\% Spermatozoa & 44.05 & 17.05 & 38.9 \\
VCL $\left(\mu \mathrm{m} \mathrm{s}^{-1}\right)$ & $109.19 \pm 0.17^{\mathrm{a}}$ & $62.42 \pm 0.26^{\mathrm{b}}$ & $29.81 \pm 0.12^{\mathrm{c}}$ \\
VSL $\left(\mu \mathrm{m} \mathrm{s}^{-1}\right)$ & $63.90 \pm 0.21^{\mathrm{a}}$ & $44.21 \pm 0.24^{\mathrm{b}}$ & $6.06 \pm 0.04^{\mathrm{c}}$ \\
VAP $\left(\mu \mathrm{m} \mathrm{s}^{-1}\right)$ & $84.07 \pm 0.18^{\mathrm{a}}$ & $53.64 \pm 0.27^{\mathrm{b}}$ & $15.46 \pm 0.09^{\mathrm{c}}$ \\
Linearity $(\%)$ & $56.84 \pm 0.15^{\mathrm{b}}$ & $68.16 \pm 0.15^{\mathrm{a}}$ & $20.14 \pm 0.09^{\mathrm{c}}$ \\
Straightness $(\%)$ & $74.30 \pm 0.15^{\mathrm{b}}$ & $81.48 \pm 0.14^{\mathrm{a}}$ & $39.30 \pm 0.16^{\mathrm{c}}$ \\
Wobble $(\%)$ & $76.04 \pm 0.09^{\mathrm{b}}$ & $83.71 \pm 0.12^{\mathrm{a}}$ & $51.00 \pm 0.12^{\mathrm{c}}$ \\
ALH $(\mu \mathrm{m})$ & $3.62 \pm 0.01^{\mathrm{a}}$ & $1.97 \pm 0.01^{\mathrm{b}}$ & $1.68 \pm 0.01^{\mathrm{c}}$ \\
BCF $(\mathrm{Hz})$ & $9.16 \pm 0.02^{\mathrm{a}}$ & $6.71 \pm 0.04^{\mathrm{b}}$ & $3.25 \pm 0.02^{\mathrm{c}}$ \\
\hline
\end{tabular}

components with eigenvalues $>1$ were identified by the PCA, accounting for $84.05 \%$ of the variance. Considering the scores of CASA parameters, the first principal component was related to fast linear movement, whereas the second was related to fast but irregular movement.

Three sperm subpopulations were defined using nonhierarchical and subsequent hierarchical classification of 45287 individual motile spermatozoa and the eight motility parameters (VCL, VSL, VAP, LIN, STR, WOB, ALH and BCF). Summary statistics for the motility characteristics of the subpopulations are given in Table 4.

Subpopulation 1 (sP1) included highly active but nonprogressive spermatozoa (highest VCL, ALH and BCF values, together with low LIN and STR values), accounting for $44.05 \%$ of the total motile population. Subpopulation 2 (sP2) contained the lowest number of spermatozoa $(17.05 \%)$ and included spermatozoa with relatively low velocity (medium VCL, VSL and VAP) but high progressiveness (high LIN, STR, WOB and low ALH). Subpopulation 3 ( $\mathrm{sP} 3$ ) included spermatozoa with less vigorous movements (low VCL, VAP, ALH and BCF) and less progressiveness (low VSL, LIN and STR) than all other groups and $38.9 \%$ of the population consisted of total motile spermatozoa. The proportion of spermatozoa assigned to sP2 (moderately slow but progressive sperm) and sP3 (slow and nonprogressive sperm) was significantly lower in the HI group $(P<0.05$; Table 5$)$, whereas the HI group had a significantly higher proportion of sP1 spermatozoa (highly active but nonprogressive).

\section{Bull fertility under field conditions}

Analysis of the mating records of the 11 bulls studied showed a CI significantly higher in the HI compared with NI group (15.07 vs 14.44 months, respectively; $P<0.05$ ). Bull effect and age of the cow (included as a covariate) were not significant, suggesting that the differences between groups could be explained, in part, by inbreeding.
Table 5. Changes in the frequency of sperm subpopulations sP1, sP2 and sP3 in semen samples from inbred (HI; $n=30)$ and non-inbred (NI; $n=25$ ) bulls

$* P<0.05$ compared with HI bulls within columns (Chi-squared test)

\begin{tabular}{llll}
\hline & sP1 (\%) & sP2 (\%) & sP3 (\%) \\
\hline HI bulls & 48.2 & 16.6 & 35.2 \\
NI bulls & $40.0^{*}$ & $17.4^{*}$ & $42.5 *$ \\
\hline
\end{tabular}

Table 6. Assessment of field fertility of inbred bulls: differences between the best and the worst solutions for each genetic and nongenetic effect studied

$* P<0.05$. HYS, herd-year-season of first calving; PEE, permanent environmental effect

\begin{tabular}{lcc}
\hline Effect & Range solutions (months) & Variance components ratio (\%) \\
\hline HYS & 17.89 & 39.83 \\
Cow age & 2.63 & \\
Cow genetic & 2.43 & 4.98 \\
Bull PEE & 7.53 & 2.432 \\
Bull genetic & 1.48 & 0.839 \\
& Regression coefficient \\
$\mathrm{Fi}^{\mathrm{A}}$ cow & $0.176^{*}$ & \\
$\mathrm{Fi}^{\mathrm{A}}$ bull & 0.089 & \\
\hline
\end{tabular}

${ }^{A}$ Inbreeding depression effect (months/percentage increase of inbreeding).

Results of extended genetic analysis, showing differences between the best and worst solutions for each effect in our animal model are given in Table 6. The largest difference, accounting for nearly $40 \%$ of the CI variability, was determined by the contemporary group. This effect is produced by the combination of herd, year, mating time of the year and therefore, environmental effects. A marked influence was also found for cow genetics (4.98\% of CI variability) and permanent environmental effect of the bull (PEE) (2.4\% of CI variability but with differences up to 7.53 months among bulls). In contrast, the genetic effect of the bull $(\mathrm{F})$ was very limited $(0.839 \%$, with differences of 1.48 among bulls). Finally, regression analysis of the effects of inbreeding on CI was significant for cows $(P<0.05)$ but not for bulls.

\section{Discussion}

Inbreeding has been widely described as a genetic trait that could adversely affect sperm quality in wild mammals (Shivaji et al. 1998; Asa et al. 2007; Ruiz-Lopez et al. 2010), domestic cats (Pukazhenthi et al. 2006), horses (van Eldik et al. 2006) and even cattle (Maximini et al. 2011). However, to our knowledge, the present study is the first comprehensive analysis assessing the effect of high inbreeding values (mean $\mathrm{F}=16.3 \%$ ) on sperm motility traits using computerised methods. In cattle, results from previous studies evaluating the inbreeding effect on spermatozoa are not consistent. For example, Flade and Zeller (1992) evaluated semen of experimentally produced inbred bulls $(\mathrm{F}=25 \%$ vs $\mathrm{F}=0 \%)$ and did not find any differences. 
In contrast, Maximini et al. (2011) demonstrated a correlation between $\mathrm{F}$ and four sperm traits (sperm volume, total sperm number, viability and subjective motility). Interestingly, both studies were performed using subjective methods (direct observation and sample classification over a motility scale of 1-5). This methodology has been reported to be less accurate and highly affected by technicians, with differences among raters of up to $30 \%$ for the same sample (Amann 1989; Verstegen et al. 2005). In the present study, such methodological differences were ruled out because kinetic assessments were performed by using an automated computerised system (CASA).

Several studies have reported that inbreeding depression increases the number of spermatozoa with abnormal morphology in both wild and domestic animals (Gomendio et al. 2000; Gage et al. 2006; Pukazhenthi et al. 2006; van Eldik et al. 2006; Asa et al. 2007). However, knowledge of the effects of inbreeding depression on cattle spermatozoa is limited (Losdat et al. 2014). In the present study, no significant differences were found between HI and NI animals in terms of sperm morphology. The same results were observed for sperm viability and acrosomal status. These results are in agreement with those reported by Flade and Zeller (1992) and Ducrocq and Humblot (1995), because they show a slight but non-significant increase in the percentage of ASM associated with higher inbreeding values. More recently, Godfrey and Dodson (2005) confirmed the absence of such a correlation. In contrast, increased DNA instability or an increased percentage of immature spermatozoa were largely related to increased ASM (Persson and Soderquist 2005; Enciso et al. 2011a). In the present study, neither DFI nor HDS differed significantly between the HI and NI groups, which is in line with the lack of differences in sperm morphology between groups.

Studies assessing the effects of inbreeding on sperm osmotic resistance in mammals are scarce till now. To our knowledge, this is the first study on this topic performed in cattle. Our findings indicate that there is no effect of inbreeding on sperm osmotic tolerance in bulls. Previous studies reported decreased tolerance to osmotic stress in inbred wild mice reared in captivity (Malo et al. 2010), but these findings were associated with sperm morphological abnormalities. Conversely, Garde et al. (2003) found a relationship between $\mathrm{F}$ and sperm osmotic resistance in some species of gazelle. However, they were highly affected by the species studied and so they cannot be extrapolated across different genera. In the same way, Walters et al. (2005) demonstrated that spermatozoa of inbred strains of mice (C57BL/6 and DBA/2N) were highly sensitive to hypoosmotic conditions, mostly because of alterations in mitochondrial morphology and function, leading to decreased resistance to cryopreservation. Despite the fact that some of these morphologically altered spermatozoa could regain motility, their ability to fertilise an oocyte may still be compromised (Nishizono et al. 2004). In the present study, there were no differences in the proportion of HOS+ spermatozoa or ASM and VS between the HI and LE groups. Furthermore, although some motility parameters, mostly associated with sperm hyperactivation, were increased in inbred spermatozoa, field fertility of the HI bulls was decreased, suggesting that sperm structure and osmotic resistance are not affected by inbreeding in cattle.
Thus, the decreased fertility observed in inbred bulls could be more likely related to kinetic than other sperm traits.

The genetic effect on DFI in cattle spermatozoa was recently studied by Karoui et al. (2012), who reported that only a minimum percentage of the variability $(<2.5 \%)$ was explained by genetic causes. Similar findings were made in the present study: DFI was not significantly affected by inbreeding, despite the $\mathrm{F}$ values were higher in the present study than those reported by Karoui et al. (2011) (16\% vs 5.3\%, respectively). However, Ruiz-Lopez et al. (2010) and Petrovic et al. (2013) demonstrated a clear correlation between DFI and inbreeding in wild ungulates and rams. This could be explained by differential resistance to oxidative stress and DNA fragmentation of spermatozoa from different species, which was also established by Enciso et al. (2011b). Interestingly, the results of the present study showed a larger than expected variability within groups despite the high number of spermatozoa analysed for each animal (at least 80000 ), suggesting that DFI is more affected by bull factors (genetic background plus environmental factors) rather than inbreeding alone. Conversely, the lack of differences in percentage HDS, a marker related to sperm maturation by Rybar et al. (2004), in association with a normal percentage of ASM suggests that inbreeding depression does not affect or impair spermatogenesis.

The negative effect of inbreeding on sperm motility has been well documented in several species, including horses (van Eldik et al. 2006), mice (Songsasen and Leibo 1997) and wild herbivores (Gomendio et al. 2000). In contrast, results for cattle show a neutral (Flade and Zeller 1992; Karoui et al. 2011) to very low (Ducrocq and Humblot 1995) effect. The present study, by assessing an extended set of CASA-derived motility parameters, allowed us to draw more accurate conclusions. The increase in kinetic parameters (VCL, VSL, VAP and ALH) in HI bulls was associated with increased velocity, erratic tracks and unexpected direction changes, typical behaviour of hyperactivated (HA) spermatozoa (Cancel 2000). Motility results were corroborated by subpopulation clustering, with the proportion of sP1 spermatozoa (highly active but non-progressive), a pattern also associated with hyperactivation (Muiño et al. 2008), being considerably increased in the HI group. Although this movement is important for egg penetration, premature sperm hyperactivation could impair sperm transport along the lower female reproductive tract (Olds-Clarke and Wivell 1992). This effect has been reported in mice, in which epididymal motility was increased in inbred strains but fertility was reduced (Carey and Olds-Clarke 1980), and in donkeys, where individuals with a higher percentage of HA spermatozoa were less fertile (Dorado et al. 2013). Therefore, we hypothesise that the early sperm hyperactivation observed in HI bulls could hinder access of the spermatozoa to the fertilisation site because of the premature exhaustion of energy reserves, subsequently reducing their fertilisation capacity. This hypothesis is in agreement with the results of the field fertility analysis, which showed significantly increased CI for calves derived from HI bulls. Interestingly, when we selected the animals for the experimental design, we noticed that bulls with such extreme F percentages were used commercially as sires. In our case (Retinta bulls), ANCRE by-laws do not prohibit their use and some breeders, against the 
genetic counselling provided by the association, only take into account bull morphology and 'pedigree' to select future sires.

It is well known that the genetic response to selection is less efficient for reproductive traits, and even less for fertility, than for several productive traits because reproduction is strongly affected by non-genetic components (reproductive diseases, nutritional status, herd management, year) and has already been affected by natural selection over several generations. However, the results of the present study showed that, in the absence of external factors, HI bulls had an impaired reproductive performance and an extended CI (0.6278 extra months on average) under field conditions compared with NI bulls. These findings agree with those of Charlesworth and Willis (2009), who demonstrated that the increase in homozygosity and the overexpression of deleterious recessive alleles (partial dominance) affect the reproductive performance of animals and suggested that $\mathrm{F}$ values must be included in any selection scheme in cattle.

A broader genetic analysis of the ANCRE database (159 bulls) was performed using a restricted maximum likelihood (REML) animal model. This methodology takes into account several genetic and non-genetic effects very efficiently, including all the relationship information among animals at any level. In the present study, with this analysis, we demonstrated that CI was highly influenced by the sire. However, most of this effect was explained by non-genetic factors, such as herd-year-season (HYS) of first calving or PEE. These results agree with those of Mackinnon et al. (1990), who found that the male component of fertility under extensive breeding systems with a prevalence of natural mating is larger than in populations with heavy use of AI. In the present study these results were unexpected because Retinta bulls are screened to avoid the use of individuals with poor sperm quality. Therefore, we hypothesise that such differences could be explained by sperm parameters not included in the basic semen analysis performed, such as the detection of premature hyperactivated motility. Conversely, the effect of inbreeding on CI was better explained by the F value of the cow than the mating bull ( $4.98 \%$ vs $0.84 \%$, respectively). This has also been reported by González-Recio et al. (2007) and McParland et al. (2009), who found lower pregnancy rates associated with highly inbred cows. However, the joint analysis of both genetic studies (higher CIs on HI bulls in narrow model and no differences in extended model) may suggest that the effect of inbreeding on sperm is only significant when certain $\mathrm{F}$ value threshold is reached (13.5\% in our case). These results agree with previous studies assessing the productive traits of dairy cows, where an inbreeding 'threshold' was also proposed (Hansen 2000; Sewalem et al. 2006).

\section{Conclusions}

In the present study, using objective and automated methodology, we demonstrated for the first time that inbreeding affects bull sperm motility. Inbred bulls showed a premature hyperactive-like motility pattern, associated with increased sperm velocity (VCL, VSL and VAP) and ALH. In addition, cows mated with inbred bulls had an increased CI under field conditions. However, we cannot determine whether the reproductive impairment observed was caused by effects associated with the spermatozoa (premature hyperactivation) or inbreeding (partial dominance, overdominance or epistasis). Further complex experiments including genotyping (single nucleotide polymorphism array genotyping or full sequencing) of embryos produced from highly and non-inbred animals are needed to clarify this issue.

\section{Acknowledgements}

The authors thank the Asociación Nacional de Criadores de Ganado Vacuno Selecto de Raza Retinta for the samples and the pedigree and reproductive records of the animals studied. The flow cytometer was kindly provided by Professor José Manuel Villalba Montoro. The authors also thank Adriana Di Maggio for English language editing. This study was supported by the MERAGEM (AGR-158) and Veterinary Reproduction Group (AGR-275), University of Cordoba, Spain.

\section{References}

Amann, R. P. (1989). Can the fertility potential of a seminal sample be predicted accurately? J. Androl. 10, 89-98.

Asa, C., Miller, P., Agnew, M., Rebolledo, J. A. R., Lindsey, S. L., Callahan, M., and Bauman, K. (2007). Relationship of inbreeding with sperm quality and reproductive success in Mexican gray wolves. Anim. Conserv. 10, 326-331. doi:10.1111/J.1469-1795.2007.00116.X

Brito, L. F., Silva, A. E., Rodrigues, L. H., Vieira, F. V., Deragon, L. A., and Kastelic, J. P. (2002). Effects of environmental factors, age and genotype on sperm production and semen quality in Bos indicus and Bos taurus AI bulls in Brazil. Anim. Reprod. Sci. 70, 181-190. doi:10.1016/S03784320(02)00009-X

Cancel, A. M. (2000). Objective evaluation of hyperactivated motility in rat spermatozoa using computer-assisted sperm analysis. Hum. Reprod. 15 , 1322-1328. doi:10.1093/HUMREP/15.6.1322

Carey, J. E., and Olds-Clarke, P. (1980). Differences in sperm function in vitro but not in vivo between inbred and random-bred mice. Gamete Res. 3, 9-15. doi:10.1002/MRD.1120030103

Carvajal-Rodriguez, A., and de Uña-Alvarez, J. (2011). Assessing significance in high-throughput experiments by sequential goodness of fit and q-value estimation. PLoS One 6, e24700. doi:10.1371/JOURNAL. PONE.0024700

Cassinello, J., Abaigar, T., Gomendio, M., and Roldan, E. R. (1998) Characteristics of the semen of three endangered species of gazelles (Gazella dama mhorr, G. dorcas neglecta and G. cuvieri). J. Reprod. Fertil. 113, 35-45. doi:10.1530/JRF.0.1130035

Charlesworth, D., and Willis, J. H. (2009). The genetics of inbreeding depression. Nat. Rev. Genet. 10, 783-796. doi:10.1038/NRG2664

Demyda-Peyras, S., Dorado, J., Hidalgo, M., De Luca, L., Muñoz-Serrano, A., and Moreno-Millan, M. (2012). In vitro induction of the acrosome reaction in spermatozoa from endangered spanish bulls: effect of breed, culture media and incubation time. Livest. Sci. 149, 275-281. doi:10.1016/J.LIVSCI.2012.07.025

Dorado, J., Acha, D., Ortiz, I., Gálvez, M. J., Carrasco, J. J., Díaz, B., GómezArrones, V., Calero-Carretero, R., and Hidalgo, M. (2013). Relationship between conventional semen characteristics, sperm motility patterns and fertility of andalusian donkeys (Equus asinus). Anim. Reprod. Sci. 143, 64-71. doi:10.1016/J.ANIREPROSCI.2013.10.003

Ducrocq, V., and Humblot, P. (1995). Genetic characteristics and evolution of semen production of young Normande bulls. Livest. Prod. Sci. 41, 1-10. doi:10.1016/0301-6226(94)00029-7

Enciso, M., Cisale, H., Johnston, S. D., Sarasa, J., Fernandez, J. L., and Gosalvez, J. (2011a). Major morphological sperm abnormalities in the bull are related to sperm DNA damage. Theriogenology 76, 23-32. doi:10.1016/J.THERIOGENOLOGY.2010.12.034 
Enciso, M., Johnston, S. D., and Gosalvez, J. (2011b). Differential resistance of mammalian sperm chromatin to oxidative stress as assessed by a twotailed comet assay. Reprod. Fertil. Dev. 23, 633-637. doi:10.1071/ RD10269

Evenson, D., and Jost, L. (2000). Sperm chromatin structure assay is useful for fertility assessment. Methods Cell Sci. 22, 169-189. doi:10.1023/ A: 1009844109023

Flade, D., and Zeller, K. (1992). Examination of the spermatozoa vitality and morphology on frozen semen from inbred bulls compared with noninbred half brothers. Arch. Tierz. 35, 327-333.

Gage, M. J. G., Surridge, A. K., Tomkins, J. L., Green, E., Wiskin, L., Bell, D. J., and Hewitt, G. M. (2006). Reduced heterozygosity depresses sperm quality in wild rabbits, Oryctolagus cuniculus. Curr. Biol. 16, 612-617. doi:10.1016/J.CUB.2006.02.059

Gandini, G., Stella, A., Del Corvo, M., and Jansen, G. B. (2014). Selection with inbreeding control in simulated young bull schemes for local dairy cattle breeds. J. Dairy Sci. 97, 1790-1798. doi:10.3168/JDS.2013-7184

Garde, J. J., Soler, A. J., Cassinello, J., Crespo, C., Malo, A. F., Espeso, G., Gomendio, M., and Roldan, E. R. (2003). Sperm cryopreservation in three species of endangered gazelles (Gazella cuvieri, G. dama mhorr, and G. dorcas neglecta). Biol. Reprod. 69, 602-611. doi:10.1095/ BIOLREPROD.102.012914

Gil, J., Januskauskas, A., Haard, M., Haard, M., Johanisson, A., Soderquist, L., and Rodriguez-Martinez, H. (2000). Functional sperm parameters and fertility of bull semen extended in Biociphos-plus ${ }^{\circledR}$ and triladyl ${ }^{\circledR}$. Reprod. Domest. Anim. 35, 69-77. doi:10.1046/J.1439-0531.2000. 00197.X

Godfrey, R. W., and Dodson, R. E. (2005). Breeding soundness evaluations of senepol bulls in the US virgin islands. Theriogenology 63, 831-840. doi:10.1016/J.THERIOGENOLOGY.2004.05.001

Gomendio, M., Cassinello, J., and Roldan, E. R. S. (2000). A comparative study of ejaculate traits in three endangered ungulates with different levels of inbreeding: fluctuating asymmetry as an indicator of reproductive and genetic stress. Proc. R. Soc. B Biol. Sci. 267, 875-882. doi:10.1098/RSPB.2000.1084

González-Recio, O., López de Maturana, E., and Gutiérrez, J. P. (2007). Inbreeding depression on female fertility and calving ease in Spanish dairy cattle. J. Dairy Sci. 90, 5744-5752. doi:10.3168/JDS.2007-0203

Gutierrez, J. P., and Goyache, F. (2005). A note on endog: a computer program for analysing pedigree information. J. Anim. Breed. Genet. 122, 172-176. doi:10.1111/J.1439-0388.2005.00512.X

Hansen, L. B. (2000). Consequences of selection for milk yield from a geneticist's viewpoint. J. Dairy Sci. 83, 1145-1150. doi:10.3168/JDS. S0022-0302(00)74980-0

Hidalgo, M., and Dorado, J. (2009). Objective assessment of goat sperm head size by computer-assisted sperm morphometry analysis (ASMA). Small Rumin. Res. 87, 108-110. doi:10.1016/J.SMALLRUMRES.2009. 10.006

Karoui, S., Díaz, C., Serrano, M., Cue, R., Celorrio, I., and Carabaño, M. J. (2011). Time trends, environmental factors and genetic basis of semen traits collected in holstein bulls under commercial conditions. Anim. Reprod. Sci. 124, 28-38. doi:10.1016/J.ANIREPROSCI.2011.02.008

Karoui, S., Díaz, C., González-Marín, C., Amenabar, M. E., Serrano, M., Ugarte, E., Gosálvez, J., Roy, R., López-Fernández, C., and Carabaño, M. J. (2012). Is sperm DNA fragmentation a good marker for field AI bull fertility? J. Anim. Sci. 90, 2437-2449. doi:10.2527/JAS.2011-4492

Kathiravan, P., Kalatharan, J., Karthikeya, G., Rengarajan, K., and Kadirvel, G. (2011). Objective sperm motion analysis to assess dairy bull fertility using computer-aided system: a review. Reprod. Domest. Anim. 46, 165-172. doi:10.1111/J.1439-0531.2010.01603.X

Keller, L. F., and Waller, D. M. (2002). Inbreeding effects in wild populations. Trends Ecol. Evol. 17, 230-241. doi:10.1016/S0169-5347(02) 02489-8
Kristensen, T. N., Pedersen, K. S., Vermeulen, C. J., and Loeschcke, V. (2010). Research on inbreeding in the 'omic' era. Trends Ecol. Evol. 25, 44-52. doi:10.1016/J.TREE.2009.06.014

Lacy, R. C. (1997). Importance of genetic variation to the viability of mammalian populations. J. Mammal. 78, 320-335. doi:10.2307/ 1382885

Leberg, P. L., and Firmin, B. D. (2008). Role of inbreeding depression and purging in captive breeding and restoration programmes. Mol. Ecol. 17, 334-343. doi:10.1111/J.1365-294X.2007.03433.X

Legarra, A., Varona, L., and López de Maturana, E. (2008). 'TM \& GS3 \& BLUP_GEN \& BLUP_SNP. Software for Threshold and Censored Models, and Genomic Selection.' Available at http://snp.toulouse.inra. $\mathrm{fr} / \sim$ alegarra [verified 23 November 2015].

Leroy, G. (2014). Inbreeding depression in livestock species: review and meta-analysis. Anim. Genet. 45, 618-628. doi:10.1111/AGE.12178

Losdat, S., Chang, S. M., and Reid, J. M. (2014). Inbreeding depression in male gametic performance. J. Evol. Biol. 27, 992-1011. doi:10.1111/ JEB. 12403

Mackinnon, M. J., Taylor, J. F., and Hetzel, D. J. (1990). Genetic variation and covariation in beef cow and bull fertility. J. Anim. Sci. 68, 1208-1214.

Malo, A. F., Martinez-Pastor, F., Alaks, G., Dubach, J., and Lacy, R. C. (2010). Effects of genetic captive-breeding protocols on sperm quality and fertility in the white-footed mouse. Biol. Reprod. 83, 540-548. doi:10.1095/BIOLREPROD.110.085316

Martinez-Pastor, F., Garcia-Macias, V., Alvarez, M., Herraez, P., Anel, L., and De Paz, P. (2005). Sperm subpopulations in Iberian red deer epididymal sperm and their changes through the cryopreservation process. Biol. Reprod. 72, 316-327. doi:10.1095/BIOLREPROD.104. 032730

Martz, E. (1992-2001). 'MFI: a Flow Cytometry List Mode Data Analysis Program Optimized for Batch Processing Under MS-DOS.’ Available at http://www.umass.edu/microbio/mfi [verified 23 November 2015].

Mathevon, M., Buhr, M. M., and Dekkers, J. C. (1998). Environmental, management, and genetic factors affecting semen production in holstein bulls. J. Dairy Sci. 81, 3321-3330. doi:10.3168/JDS.S0022-0302(98) 75898-9

Maximini, L., Fuerst-Waltl, B., Gredler, B., and Baumung, R. (2011). Inbreeding depression on semen quality in Austrian dual-purpose simmental bulls. Reprod. Domest. Anim. 46, e102-e104. doi:10.1111/ J.1439-0531.2010.01645.X

McParland, S., Kearney, F., and Berry, D. P. (2009). Purging of inbreeding depression within the Irish holstein-friesian population. Genet. Sel. Evol. 41, 16. doi:10.1186/1297-9686-41-16

Muiño, R., Tamargo, C., Hidalgo, C. O., and Peña, A. I. (2008). Identification of sperm subpopulations with defined motility characteristics in ejaculates from holstein bulls: effects of cryopreservation and betweenbull variation. Anim. Reprod. Sci. 109, 27-39. doi:10.1016/J.ANIRE PROSCI.2007.10.007

Nishizono, H., Shioda, M., Takeo, T., Irie, T., and Nakagata, N. (2004). Decrease of fertilizing ability of mouse spermatozoa after freezing and thawing is related to cellular injury. Biol. Reprod. 71, 973-978. doi:10.1095/BIOLREPROD.103.024422

O’Grady, J. J., Brook, B. W., Reed, D. H., Ballou, J. D., Tonkyn, D. W., and Frankham, R. (2006). Realistic levels of inbreeding depression strongly affect extinction risk in wild populations. Biol. Conserv. 133, 42-51. doi:10.1016/J.BIOCON.2006.05.016

Olds-Clarke, P., and Wivell, W. (1992). Impaired transport and fertilization in vivo of calcium-treated spermatozoa from $+/+$ or congenic $\mathrm{t}(\mathrm{w} 32) /+$ mice. Biol. Reprod. 47, 621-628. doi:10.1095/BIOLREPROD47.4.621

Persson, Y., and Soderquist, L. (2005). The proportion of beef bulls in Sweden with mature spermiograms at 11-13 months of age. Reprod. Domest. Anim. 40, 131-135. doi:10.1111/J.1439-0531.2005.00567.X 
Petrovic, V. C., Maksimovic, N., Petrovic, M. P., Petrovic, M. M., Ilic, Z. Z. Muslic, D. R., and Mikulec, D. P. (2013). Effect of inbreeding on body growth traits and sperm DNA fragmentation level in rams. Anim. Sci. Pap. Rep. 31, 27-33.

Pukazhenthi, B. S., Neubauer, K., Jewgenow, K., Howard, J., and Wildt, D. E. (2006). The impact and potential etiology of teratospermia in the domestic cat and its wild relatives. Theriogenology 66, 112-121. doi:10.1016/J.THERIOGENOLOGY.2006.03.020

Revell, S. G., and Mrode, R. A. (1994). An osmotic resistance test for bovine semen. Anim. Reprod. Sci. 36, 77-86. doi:10.1016/0378-4320(94) 90055-8

Rodero-Serrano, E., Demyda-Peyrás, S., González-Martinez, A., RoderoFranganillo, A., and Moreno-Millán, M. (2013). The rob(1;29) chromosome translocation in endangered Andalusian cattle breeds. Livest. Sci. 158, 32-39. doi:10.1016/J.LIVSCI.2013.10.001

Rodriguez-Martinez, H., and Larsson, B. (1998). Assessment of sperm fertilizing ability in farm animals. Acta Agr. Scand. A Anim. Sci. 29(Suppl.), 12-18.

Ruiz-Lopez, M. J., Evenson, D. P., Espeso, G., Gomendio, M., and Roldan, E. R. (2010). High levels of DNA fragmentation in spermatozoa are associated with inbreeding and poor sperm quality in endangered ungulates. Biol. Reprod. 83, 332-338. doi:10.1095/BIOLREPROD. 110.084798

Rybar, R., Faldikova, L., Faldyna, M., Machatkova, M., and Rubes, J. (2004). Bull and boar sperm DNA integrity evaluated by sperm chromatin structure assay in the Czech Republic. Vet. Med. Czech. 49, 1-8.

Rybar, R., Kopecka, V., Prinosilova, P., Kubickova, S., Veznik, Z., and Rubes, J. (2010). Fertile bull sperm aneuploidy and chromatin integrity in relationship to fertility. Int. J. Androl. 33, 613-622.

Sewalem, A., Kistemaker, G. J., Miglior, F., and Van Doormaal, B. J. (2006). Analysis of inbreeding and its relationship with functional longevity in Canadian dairy cattle. J. Dairy Sci. 89, 2210-2216. doi:10.3168/JDS. S0022-0302(06)72291-3

Shivaji, S., Jayaprakash, D., and Patil, S. B. (1998). Assessment of inbreeding depression in big cats: testosterone levels and semen analysis. Curr. Sci. 75, 923-930.
Smith, L. A., Cassell, B. G., and Pearson, R. E. (1998). The effects of inbreeding on the lifetime performance of dairy cattle. J. Dairy Sci. 81, 2729-2737. doi:10.3168/JDS.S0022-0302(98)75830-8

Söderquist, L., Janson, L., Håård, M., and Einarsson, S. (1996). Influence of season, age, breed and some other factors on the variation in sperm morphological abnormalities in Swedish dairy A.I. bulls. Anim. Reprod. Sci. 44, 91-98. doi:10.1016/0378-4320(96)01498-4

Songsasen, N., and Leibo, S. P. (1997). Cryopreservation of mouse spermatozoa II. Relationship between survival after cryopreservation and osmotic tolerance of spermatozoa from three strains of mice. Cryobiology 35, 255-269. doi:10.1006/CRYO.1997.2047

Sørensen, A. C., Sørensen, M. K., and Berg, P. (2005). Inbreeding in danish dairy cattle breeds. J. Dairy Sci. 88, 1865-1872. doi:10.3168/JDS S0022-0302(05)72861-7

Stachowicz, K., Sargolzaei, M., Miglior, F., and Schenkel, F. S. (2011). Rates of inbreeding and genetic diversity in Canadian holstein and jersey cattle. J. Dairy Sci. 94, 5160-5175. doi:10.3168/JDS.2010-3308

Thompson, J. R., Everett, R. W., and Hammerschmidt, N. L. (2000). Effects of inbreeding on production and survival in holsteins. J. Dairy Sci. 83, 1856-1864. doi:10.3168/JDS.S0022-0302(00)75057-0

Tier, B. (1990). Computing inbreeding coefficients quickly. Genet. Sel. Evol. 22, 419-430. doi:10.1186/1297-9686-22-4-419

van Eldik, P., van der Waaij, E. H., Ducro, B., Kooper, A. W., Stout, T. A., and Colenbrander, B. (2006). Possible negative effects of inbreeding on semen quality in Shetland pony stallions. Theriogenology $\mathbf{6 5}$, 1159-1170. doi:10.1016/J.THERIOGENOLOGY.2005.08.001

Verstegen, J. P., Onclin, K., and Iguer-Ouada, M. (2005). Long-term motility and fertility conservation of chilled canine semen using egg yolk added Tris-glucose extender: in vitro and in vivo studies. Theriogenology 64, 720-733. doi:10.1016/J.THERIOGENOLOGY.2005.05.035

Walters, E. M., Men, H., Agca, Y., Mullen, S. F., Critser, E. S., and Critser, J. K. (2005). Osmotic tolerance of mouse spermatozoa from various genetic backgrounds: acrosome integrity, membrane integrity, and maintenance of motility. Cryobiology 50, 193-205. doi:10.1016/ J.CRYOBIOL.2005.01.004

Wright, S. (1931). Evolution in Mendelian populations. Genetics 16 $97-159$. 